\section{A Field Note Describing the Development and Dissemination of Clear Language Research Summaries for University-Based Knowledge Mobilization}

\author{
David J. Phipps, Krista E. Jensen, \& Michael Johnny \\ York University
}

Gary Myers

KMbeing.com
Scholarly and Research

Communication

VOLUME 4 / ISSUE 1 / 2013

\begin{abstract}
\section{Objectives}

The outputs of academic research are often written in technical language that is not accessible or useful to non-academic audiences. We set out to develop and disseminate clear language research summaries as one element of York University's Knowledge Mobilization (KMb) strategy. This field note describes how we developed, evaluated, and disseminated clear language research summaries as tools for research outreach and communication.
\end{abstract}

\section{Methods AND Results}

We worked under the auspices of a Steering Committee of research stakeholders and under the instruction of a clear language writing and design specialist to develop research summaries in a format that would comply with clear language writing and design principles. This format was tested in roundtables of diverse research stakeholders and has received positive feedback from diverse research users. The research summaries were made accessible online and disseminated using a social media strategy. The use of Twitter to enhance dissemination of the research summaries increased web traffic to the research summary database by $270 \%$.

\footnotetext{
CCSP Press

Scholarly and Research Communication

Volume 4, Issue 1, Article ID 010503, 17 pages Journal URL: www.src-online.ca Received January 22, 2011, Accepted May 30, 2012, Published October 1, 2012

David Phipps, Krista E. Jensen, Michael Johnny, Gary Myers. (2012). Field Note: Research Summaries Improve Access and Utility of Academic Research. Scholarly and Research Communication, 4(1): 010503, $17 \mathrm{pp}$.

(C) 2012 David Phipps. This Open Access article is distributed under the terms of the Creative Commons Attribution Non-Commercial License (http://creativecommons.org/licenses/by-nc-nd/2.5/ ca), which permits unrestricted non-commercial use, distribution, and reproduction in any medium, provided the original work is properly cited.
}

David J. Phipps, PhD, MBA, is Executive Director Innovation Services, York University. Email: dphipps@yorku.ca.

Krista E. Jensen is the Knowledge Mobilization Officer in the Knowledge Mobilization Unit at York University. Email: kejensen@ yorku.ca.

Michael Johnny is Manager, Knowledge Mobilization, York University. Email: mjohnny@ yorku.ca.

Gary Myers is a community based researcher and author of the KMbeing blog (www. kmbeing.com). Email: kmbeing@gmail.com. 
Scholarly and Research

Communication

VOLUME 4 / ISSUE 1 / 2013

\section{Conclusions}

We find that clear language research summaries are appealing to non-academic decision-makers and can be used to disseminate research findings to a wide online audience. Based on this feedback we have adopted this standard research summary format as part of an institutional knowledge mobilization strategy. Providing greater access to research summaries has the potential to connect decision-makers and communities to academic researchers, which ultimately helps academic research to inform decision-making.

\section{Keywords}

Research summary; Clear language; Knowledge mobilization

\section{Goal of the field note}

This field note is formatted in the style of the clear language research summaries, providing details on: "What is this about?"; "What did we do?"; "What did we find?"; "How can you use this?"; and ending with "What you need to know." The aim of this field note is to provide information about the development and dissemination of clear language summaries as tools for research outreach, research communications, and Knowledge Mobilization (KMb). This field note provides details on the ResearchSnapshot clear language research summaries as models that can be adopted by others who wish to disseminate published research findings in a clear, concise, and accessible format. This article also makes recommendations on the production and use of clear language research summaries for different research producer and user audiences. Our goal is to help knowledge brokers, universities, and other research institutions, including community-based researchers, learn from our journey as they consider their own approaches to services supporting research outreach and communication.

What is this ReSearch about? Clear language Research SUMmaries AS TOOLS FOR INSTITUTIONAL KNOWLEDGE MOBILIZATION

As part of a university outreach strategy engaging diverse non-academic communities (including businesses and government agencies) in research activities, the Office of the Vice-President Research \& Innovation at York University developed Canada's first knowledge mobilization unit that is fully integrated into the university's research infrastructure (Phipps \& Shapson, 2009). KMb is an emerging institutional research infrastructure that seeks to connect academic research and expertise to non-academic individuals and organizations so that research can inform decisions about public policy and professional practice. While many $\mathrm{KMb}$ activities exist within discrete research projects, what is emerging is an institutional capacity to support the $\mathrm{KMb}$ activities of university researchers and their non-academic research stakeholders. We recently published details on York's KMb Unit (Phipps, 2011).

\section{Literature Review}

\section{KNOWLEDge Mobilization}

As an activity, $\mathrm{KMb}$ is not new. Activities analogous to $\mathrm{KMb}$ are reported as far back as the late 1800's (Murmann, 2003) and underpin traditional extension work for the US land grant universities (Ward \& Stone, 1992). More recently, frameworks for and theories of these activities have been established in fields as diverse as health 
(Estabrooks, Derksen, Winther, Lavis, Scott, Wallin, \& Profetto-McGrath, 2008;

Estabrooks, Thompson, Lovely, \& Hofmeyer, 2006), the environment (Michaels, 2009), education (Hemsley-Brown \& Sharp, 2003; Cooper \& Levin, 2010), and international development (Cash, 2003). We previously reported on $\mathrm{KMb}$ as an institutional capacity to support connections between university researchers and non-academic research stakeholders (Phipps \& Shapson, 2009) and showed that one feature of York University's KMb service is the clear language research summary, which supports a "producer push" method of KMb (Lavis, Ross McLeod, \& Gildner, 2003). In his 1946 essay "Politics and the English Language," George Orwell (1946, paragraph 20) wrote about clear language usage, stating that clear language "does imply using the fewest and shortest words that will cover one's meaning." Mazur (2000) writes of plain language writing and design principles dating to 1953 and principles of plain language have previously been used to summarize university research, but have not been adopted by university researchers who traditionally write in technical language for their peers. An exception would be the scholar who is also committed to knowledge mobilization and exchange with non-academic audiences and seeks to write in accessible language.

\section{ReSEARCH Summaries}

Research summaries come in many forms, including press releases, policy briefs, clinical practice guidelines, research fact sheets, knowledge briefs, and structured abstracts (Community Alliance for Research and Engagement, n.d.). In all of these examples, research summaries were developed to support evidence-based practice/ policy by presenting relevant research in a clear and concise manner. Clear language research summaries have also been shown to be a key tool for KMb. Meagher, Lyall, and Nutley (2008) identified a number of conditions for generating non-academic impacts from social science research. These conditions include:

- creating a two-way interaction between researchers and research users;

- making knowledge transfer infrastructure, funding, and dedicated staff accessible;

- communicating clear translations of research findings.

Similarly, Jacobson, Butterill, and Goering (2004) and their colleagues report that research summaries are a valuable KMb tool, but writing for non-academic audiences is not recognized as legitimate scholarship. Consequently, there are few incentives for researchers to produce their work in formats other than scholarly formats. This lack of incentive limits the scope of exposure to research beyond academia.

\section{What did WE Do? DeVeloping, PRODUCing, AND Disseminating Clear LANGUAGE RESEARCH SUMMARIES}

\section{Steering committee}

It was important that both research producers at York University and non-academic research users guided this project so that the end result would provide results that were relevant for a variety of audiences. The development of clear language research
VOLUME 4 / ISSUE 1 / 2013 
Scholarly and Research

\section{Communication}

VOLUME 4 / ISSUE 1 / 2013 summaries was guided by a Steering Committee representing different research stakeholders: a researcher working in homelessness (a policy relevant discipline), a provincial policy analyst, and a municipal government employee responsible for coordinating delivery of human services.

\section{Review of existing research summary formats}

A number of research summary formats were collected for review by the Steering Committee. Research summaries numbers one to six below were chosen because they were produced by the leading Canadian $\mathrm{KMb}$ organizations at the time (Summer 2008). In addition, research summaries seven to nine were chosen because they were featured by UK KMb organizations at the 2007 Campbell Collaboration Colloquium, which the authors attended.

1. Mythbusters (Canadian Health Services Research Foundation)

2. Evidence Boost (Canadian Health Services Research Foundation)

3. Fact Sheets (Canadian Centre for Knowledge Mobilization)

4. Research Spotlights (Canadian Centre for Knowledge Mobilization)

5. State of the Art Reviews (no longer available from the Canadian Centre for Knowledge Mobilization)

6. Abstract (Program in Policy Decision-Making)

7. At a Glance (Social Care Institute for Excellence)

8. Evidence Bank (Research In Practice)

9. Knowledge Library (Evidence for Policy and Practice Information and Coordinating Centre)

Each of these existing research summaries was reviewed and compared on the following characteristics: branding, length, adherence to clear language design principles (layout, font, consistent use of colour, use of key messages), and overall appeal. These were selected by the Steering Committee, who determined that these characteristics were the most attractive and useful features that were common to these nine research summaries.

In addition, the Steering Committee observed that the most effective research summaries appeared in the form of a standardized, branded research summary series. The name ResearchSnapshot was chosen to mirror the ResearchImpact name and brand (www.researchimpact.ca) of York University's KMb activities. Similarly, the design of the ResearchSnapshot logo ("summarize - mobilize") mirrored the design of the ResearchImpact logo ("turning research into action") in colour, size, font, and presentation. ResearchImpact and ResearchSnapshot are registered marks of York University, Toronto, Canada.

\section{Clear language design and writing}

Meagher et al. (2008) calls for the use of dedicated and trained staff for effective $\mathrm{KMb}$. In order to provide a service for writing clear language summaries, an adult literacy practitioner with an expertise in clear language design and writing principles was recruited to train students to write clear language research summaries. The 
practitioner facilitated eight clear language sessions that has, to date, attracted a total of 80 participants (engaging between six to eighteen participants per workshop). Using a combination of instruction and guided workshop experiences, each half day session provided details on the six steps of clear language writing and design - thinking, planning, writing, designing, testing, and revising - providing numerous examples of how to utilize these steps in everyday communications.

We have spoken with researchers who believe they already write in "clear" language, but for them "clear" language is often equated with technical language that is exacting, as judged by their peers. This is not language that is clear to a non-academic audience. Researchers also have no academic incentive to write in anything but a scholarly fashion. We therefore chose to provide training in clear language writing and design principles to graduate students. Providing a service for clear language writing rather than expecting scholars to write their own scholarship in clear language is consistent with the philosophy of the KMb Unit as a service unit of the university. However, the researchers are engaged throughout the process, from submitting published articles to be summarized to approving the final text of the research summaries.

\section{Feedback and Evaluation}

Once the ResearchSnapshot format was developed under the direction of the Steering Committee, three roundtables were undertaken to evaluate the ResearchSnapshot format. Each Steering Committee member developed a roundtable group from their constituents: researchers, community organizations, and provincial policy makers. The roundtables represented a purposive sample totalling 24 knowledge workers with diverse experiences. For example, the Ontario Ministry of Community and Social Services roundtable included individuals with expertise in research, program evaluation, policy, and operational staff. The roundtables provided an opportunity to administer a short survey and to engage in semi-structured interviews with roundtable participants. A presentation was made to roundtable participants outlining the $\mathrm{KMb}$ Unit and the research summary project. After the project was presented, an overview of the 42 available ResearchSnapshot summaries was provided. The roundtable participants were asked to complete the survey to evaluate the clear language summaries. They were also asked what additional features might be of interest to them and how they might use the research summaries in their practice.

\section{Dissemination}

A number of different dissemination strategies were employed to enhance access to ResearchSnapshot summaries. A total of 220 ResearchSnapshot summaries have been produced since 2008. These are disseminated using a searchable, online database. Relevant ResearchSnapshot summaries are presented at conferences, are subject matter for our KMb blog, and have been featured in the Globe and Mail, Canada's national newspaper (Church, 2010). Social media is a service offered by York University's Knowledge Mobilization Unit (Phipps, 2011). We chose a social media strategy to support dissemination of ResearchSnapshot clear language research summaries due to 1) the potential amplification of content through re-posting of online content and 2) possibility of feedback from and iterative dialogue with users of social media. On
VOLUME 4 / ISSUE $1 / 2013$ 
Scholarly and Research Communication

VOLUME 4 / ISSUE 1 / 2013
December 15, 2009 we began posting ResearchSnapshot summaries in a daily Twitter feature called "Today's ResearchSnapshot" using the ResearchImpact Twitter feed (@ researchimpact; http://twitter.com/researchimpact). These different strategies were chosen as they allow for both push (blog, Twitter, newspaper, and conferences) and pull (Twitter, online database) forms of dissemination, enabling us to reach a wider audience than any single dissemination method.

\section{Results}

What did We Find? Producing ResearchSnapshot Clear language RESEARCH SUMMARIES

The most desirable elements in the existing research summaries that corresponded to clear language writing and design were identified and synthesized by the Steering Committee to produce a template for the ResearchSnapshot series that contained the following elements:

1. Length: The summaries reviewed presented research results in as short as oneparagraph (Program in Policy and Decision Making abstract) and as long as four pages (State of the Art Reviews, Canadian Centre for Knowledge Mobilization). The Steering Committee recommended a length of two pages.

2. Font: Some existing research summary formats made the compromise between length and comprehensiveness of information by using a small font to pack what was considered too much information into one or two pages. The Steering Committee recommended the easy to read Arial font size twelve. It was subsequently confirmed by the clear language writing and design instructor that this font style and size is consistent with clear language design principles.

3. Design: Designed to be a series of research summaries, it was recommended that ResearchSnapshot summaries adhere to a standard format. Each ResearchSnapshot has a headline rather than the title of the paper or academic report. Each ResearchSnapshot then uses the same clear language headings:

- What is this research about (=background)

- What did the researchers do (=methods)

- What did the researchers find (=results)

- How can you use this research (=practical applications)

Lavis, Davies, Oxman, Denis, Golden-Biddle, \& Ferlie (2005) propose a 1:3:25 rule where evidence is presented in one page, three page, and 25 page formats, providing decision-makers with increasing amounts of detail. In a more compressed approach, the Steering Committee recommended each two page ResearchSnapshot use a one sentence headline and a two to three sentence abstract of the summary (contained in the "What you need to know" box on the front page) to highlight the most salient points made in the summary. This format allows the reader to easily obtain increasing amounts of information from the research summary. Each ResearchSnapshot also includes the key words identified in the publication, as well as the citation of the original paper or academic report.

Our experience is that it takes an appropriately trained student approximately oneand-a-half to two days to read the original journal article, draft a research summary, review it, and send it out for faculty approval. Additional time is required to solicit and 
select studies to be summarized. With two students engaged in full time writing over the summer, we produce approximately 40 ResearchSnapshot summaries each year. At the current student salary each ResearchSnapshot clear language research summary costs approximately $\$ 250$ to produce. In our experience, the most time-consuming step in the process is the time required to seek faculty feedback and approval.

See Appendix A for a model ResearchSnapshot using an early report of this study as the subject material.

\section{WhAT DID WE FIND? USING RESEARCHSNAPSHOT SUMMARIES}

ResearchSnapshot clear language research summaries were presented to roundtable participants who provided us with valuable feedback on the formats developed under the direction of the Steering Committee. After reviewing the research summaries, a clear majority of participants $(77.6 \%)$ rated the format to be satisfactory or higher and $86.6 \%$ rated the format to be useful or higher. Participants indicated that they found the summaries aesthetically engaging. Comments that we received on ResearchSnapshot clear language research summaries included:

- I can see non-profit organizations using these in funding applications, program planning, and to improve stakeholders/community (Interviewee 1, 2009).

- Could help substantiate a policy position or help bolster your argument.

- Useful as background information, know who to contact in policy area (Interviewee 2, 2009).

- This brings a sense of validation to the request we are making to the funder (Interviewee 3, 2009).

- Short enough to be read/scanned quickly, but enough data to give me a whole picture (Interviewee 4, 2009).

- Excellent as introduction to research (Interviewee 5, 2009).

- It is good that many summaries exist in one location (Interviewee 6, 2009).

- What you need to know section is great (Interviewee 7, 2009).

- Has great potential, but summaries are not detailed enough (Interviewee 8, 2009).

Feedback was also received from the roundtable participants and subsequently incorporated into the ResearchSnapshot format, including the addition of biographical information on the researcher ("About the researcher(s)") as well as the reference(s) used to generate the research summary. Researchers also appreciate the KMb Unit developing ResearchSnapshot for them. According to one researcher, "The KMb Unit has produced a very nice research summary (available at http://bit.ly/ausHTu ), which we have already begun to use with key decision-makers in government" (Eric Mykhalovskiy, Associate Professor, Dept. Sociology, Faculty of Liberal Arts \& Professional Studies, York University, 2010).

According to the web analytic data from our web providers, the ResearchSnapshot database received over 19,800 hits (July 2008-January 2011). Using data from Google Analytics set up in November 2009, the ResearchSnapshot database received 6,105 page views from 3,770 unique users during the period of November 2009 to January 2011. Google Analytics allows further analysis of the performance of the ResearchSnapshot web accessible database. The bounce rate (percentage of people who come to a website
VOLUME 4 / ISSUE 1 / 2013 
Scholarly and Research Communication

VOLUME 4 / ISSUE 1 / 2013 and leave without clicking on any other pages) was only $32.7 \%$ and exit rate (percentage of viewers who left the website from this page after viewing multiple pages) was only $15.2 \%$. Industry standards suggest a bounce rate of over $35 \%$ is a cause for concern and anything above $50 \%$ is worrying (Kaushik, 2007). A bounce rate of $32.7 \%$ indicates that the ResearchSnapshot web database attracts and retains viewers.

\section{What DID WE FIND? - DISSEMINATING RESEARCHSNAPSHOT SUMMARIES}

Strategies using the media and presentations at conferences and meetings provide access to ResearchSnapshot summaries; however, we chose to take a more active approach by developing a social media strategy to support dissemination of the research summaries. We began posting stories about ResearchSnapshot summaries on the ResearchImpact blog, but the greatest success as measured by hits on the online database has been the use of the ResearchImpact Twitter feed (@researchimpact). On December 15, 2009 we began to post a new ResearchSnapshot every day in a regular post called “Today's ResearchSnapshot." For example on April 8, 2010, a tweet was posted as "Today's ResearchSnapshot: CBT may help children cope with anxiety at school and in social settings http://bit.ly/bAP2gF." While we still distribute ResearchSnapshot summaries at conferences, our main route of dissemination is through our daily tweets on Twitter.

For the 17 months from the launch of the ResearchSnapshot online database (July 2008) to the month before starting "Today's ResearchSnapshot" (November 2009), the database saw an average of $322 \pm 294$ (range 20-1,163) hits per month (January 2009 was an unusual month as a delegation of Swedish researchers and university administrators was preparing for a visit and were seeking information on ResearchImpact). In the 14 months since starting "Today's ResearchSnapshot" the average monthly web hits grew to $865 \pm 457$ per month (range 471-2,339), which represents an average increase of $270 \%$. A two-tailed $t$ test for independent samples shows these two groups are significantly different $(p=0.0004$ ), allowing us to conclude that the introduction of the Twitter feature "Today's ResearchSnapshot" has had a significant and positive effect on the number of hits on the research summary database. Furthermore, Google Analytics allows us to see that more users gain access to the ResearchSnapshot database using Twitter than any other route. This increase in web traffic after several months of "Today's ResearchSnapshot" being online is not a function of growth in Twitter users. The increase in traffic to the ResearchSnapshot database has remained steady at $270 \%$ while the number of Twitter users has continued to grow. According to Twitter, as of March 14, 2011, there was average growth of 460,000 new Twitter accounts per day (Twitter Blog, 2011).

Since ResearchSnapshot summaries have been disseminated using Twitter we have received email feedback from two organizations that used ResearchSnapshot summaries in their practice.

The focus on how the reader can use the research ("How can you use this research") is helpful in shifting from a simple communication about a research study to an interpretation and contextualization of the research - moving further along the route to mobilizing the knowledge. (Heather Bullock, Centre for Addition and Mental Health, Toronto, Canada, 2010) 
I was able to include the Research Summary of the York Region Infrastructure project in [a] presentation. It provided a succinct, pertinent, and accessible way of introducing academic research into my presentation. Most helpful. (Johanna French, York Region District School Board, Canada, 2010)

Other organizations are now adopting ResearchSnapshot summaries to enhance access to their research for a broader audience. In the first half of 2011, the ResearchSnapshot format had been adopted by the University of Guelph, the Ontario Knowledge Network for Applied Education Research, and the Ontario Mental Health and Addictions Knowledge Exchange Network housed at the Centre for Additions and Mental Health (Toronto). The University of Guelph will be housing their ResearchSnapshot summaries within the university library's DSpace, which is an online open access repository and will thus be a tool used by university librarians and the stakeholders they serve. The University of Guelph will also be using the clear language text for multiple purposes including, but not limited to ResearchSnapshot clear language research summaries. The adoption of ResearchSnapshot clear language research summaries by multiple institutions will grow the library of ResearchSnapshot clear language research summaries and provide greater access to more research.

\section{HOW CAN YOU USE THIS RESEARCH?}

ResearchSnapshot summaries are not intended to directly inform practice or policy decisions. Care must be taken when using a research summary, as the results of single studies should not generally be relied on to inform decisions (Lavis, Ross, McLeod, \& Gildner, 2003). Rather, they are intended as an introduction to the research and the researcher. Because effective $\mathrm{KMb}$ occurs within the context of personal relationships (Mitton, Adair, McKenzie, Patten, Wayne-Perry, \& Smith 2009; Gagnon, 2011) and two-way personal communication (Innvaer, Vist, Trommald, \& Oxman, 2002), we use research summaries to introduce research of potential interest to collaborators.

Knowledge brokers at York University's KMb Unit use ResearchSnapshot summaries as "calling cards" to introduce non-academics and decision-makers to research expertise. More effective than the ubiquitous expertise database (which relies on self identified keywords and is usually organized along university departmental and faculty structures), the $\mathrm{KMb}$ Unit uses these research summaries to provide detailed research results in accessible language that can alert decision-makers to research expertise available for collaboration. Furthermore, relationships such as two-way exchange and knowledge sharing may also be supported by social media tools generally (Watermeyer, 2010; Sangwan, Guan, \& Siguaw, 2009) and through microblogging services such as Twitter specifically (Java, Song, Finin, \& Tseng, 2007). This is consistent with our findings that the use of Twitter (as well as blogging) can enhance web-based access to ResearchSnapshot clear language research summaries.

\section{Limitations to this field note}

While this field note provides information about the development and dissemination of clear language research summaries (the "what" of clear language research summaries), we have noted a number of limitations to our understanding of "how" effectively these clear language research summaries are being used in practice.
VOLUME 4 / ISSUE 1 / 2013 


\section{Scholarly and Research}

\section{Communication}

VOLUME 4 / ISSUE 1 / 2013
We know the ResearchSnapshot database is being accessed and the majority of that access is directed from Twitter. We know neither who is accessing the ResearchSnapshot clear language research summaries nor for what purpose. Apart from anecdotal feedback and adoption by other institutions, we have not assessed the impact of the research summaries on end users. We have considered embedding a simple pop-up questionnaire every time a user links to the ResearchSnapshot database but we suspect response rate will be low since accessing the database is not the same as using the ResearchSnapshot. Such a questionnaire may provide evidence of intent to use but not about actual use of the research summary.

The clear language practitioner we work with is an expert in clear language writing and design; however, we did not engage a design expert to complement the user expertise of the Steering Committee. It is possible that a graphic designer might have added value to the ResearchSnapshot format and would have been able to test different aspects of the design (colour, use of white space, font, and layout) for their impact on end user uptake and application. This could be the subject of future research but is beyond the scope of a field note.

The introduction of the daily Twitter post "Today's ResearchSnapshot" increased traffic to the ResearchSnapshot database by $270 \%$. We also know that Today's ResearchSnapshot is often re-tweeted, further enhancing the reach of the Today's ResearchSnapshot tweet. Honeycutt and Herring (2009) showed that Twitter users were making use of the platform for conversation, which they argue is an essential part of collaboration. Gruzd, Wellman, and Takhteyev (2011) studied one person's Twitter network, which displayed the basis for a real community, based on factors such as common language, the immediacy of information, and "high centres." High centres represent users who are leaders in each field or subject community on Twitter. York’s KMb Unit tweets as @ researchimpact and has 2,398 followers (as of May 30, 2012). Compared to other $\mathrm{KMb}$ associated organizations with a Twitter presence @researchimpact would be considered a "high centre" compared to: @KMbW_ Updates 262 followers; @KTExchange 215 followers; @CRFRTweets 348 followers; @ CuppBrighton 448 followers; @kbforum 158 followers; and @KTECoP 156 followers. Since @researchimpact is a leading Twitter user among the KMb community, the use of Twitter significantly amplifies the dissemination of the ResearchSnapshot clear language research summaries; however, more research is needed to explore not only who is accessing the research summaries but how the "signal" of the research summaries is making it through the broader "noise" of Twitter to reach their intended audiences.

These limitations create an opportunity for research by scholars interested in a detailed understanding of how clear language research summaries might influence behaviour of end users. Our understanding of the development and dissemination of clear language research summaries would be complemented by rigorous research into how research summaries might have an impact on decision making. 


\section{RECOMMENDATIONS FOR PRODUCING CLEAR LANGUAGE RESEARCH SUMMARIES}

After three years of producing ResearchSnapshot summaries we make the following recommendations about how different research stakeholders can use clear language and clear language research summaries. These observations are provided in Table 1.

Table 1: Recommendations on how different stakeholders can use clear language and clear language research summaries

\begin{tabular}{|c|c|}
\hline $\begin{array}{l}\text { Universities and } \\
\text { Research Institutions }\end{array}$ & $\begin{array}{l}\text { Clear language research summaries can be used as } \\
\text { communication vehicles to clearly communicate the } \\
\text { results of research to non-academic research audiences. } \\
\text { Clear language research summaries serve as introductions } \\
\text { to research expertise that may lead to future research } \\
\text { collaborations. } \\
\text { Teaching students to write according to clear language } \\
\text { writing and design principles provides a unique skill set } \\
\text { valuable for many non-academic careers. }\end{array}$ \\
\hline $\begin{array}{l}\text { Research Funding } \\
\text { Organizations }\end{array}$ & $\begin{array}{l}\text { Clear language research summaries can be used as } \\
\text { communication vehicles to clearly communicate the } \\
\text { outcomes of investments in research to parliamentarians, } \\
\text { donors, and other funders. } \\
\text { Clear language research summary frameworks can be } \\
\text { used to solicit end of grant research reports from grant } \\
\text { recipients. }\end{array}$ \\
\hline $\begin{array}{l}\text { Knowledge Transfer } \\
\text { and Exchange } \\
\text { Organizations }\end{array}$ & $\begin{array}{l}\text { Organizations such as the Social Care Institute for } \\
\text { Excellence or the Arthritis Society can use clear language } \\
\text { research summaries to present research to a variety of } \\
\text { decision-makers and stakeholders. }\end{array}$ \\
\hline Knowledge Brokers & $\begin{array}{l}\text { Clear language summaries can be used to communicate } \\
\text { research findings from research projects to mobilize } \\
\text { knowledge and attract interest in the research of your } \\
\text { project/unit/institution. }\end{array}$ \\
\hline $\begin{array}{l}\text { Community Based } \\
\text { Researchers }\end{array}$ & $\begin{array}{l}\text { As opposed to university-based research, community- } \\
\text { based research is inherently change-oriented. Clear } \\
\text { language research summaries are one tool to communicate } \\
\text { research to decision-makers. Working outside of an } \\
\text { academic paradigm of research, community-based } \\
\text { researchers could learn clear language writing and design } \\
\text { principles to make their research accessible. }\end{array}$ \\
\hline $\begin{array}{l}\text { Community and } \\
\text { Government } \\
\text { Decision-makers }\end{array}$ & $\begin{array}{l}\text { Seek out clear language research summaries to connect } \\
\text { to research and research expertise to inform decision } \\
\text { making. }\end{array}$ \\
\hline
\end{tabular}

\section{WHAT YOU NEED TO KNOW}

As stated in the ResearchSnapshot of this research summary project (Appendix A), "adopting a standard format that summarizes key outcomes and recommendations and providing greater access to these summaries has been demonstrated to more effectively capture and communicate the outcomes of research for non-academic audiences, 
Scholarly and Research Communication

VOLUME 4 / ISSUE 1 / 2013 connect decision-makers to academic researchers, and ultimately help academic research to inform decision-making." Our work has previously shown that developing an institutional capacity for knowledge mobilization has benefits for the institution, researchers, graduate students, and research users (Phipps \& Shapson, 2009). In response to limitations previously cited by Jacobson et al. (2004) and Meagher et al. (2008), York University is providing a funded $\mathrm{KMb}$ infrastructure, including students trained in clear language writing principles to support the connecting of university research to non-academic audiences. We produce clear language research summaries and disseminate them using a clearly articulated social media strategy as part of our broader $\mathrm{KMb}$ services that support research outreach and communication.

We believe our experience can assist other knowledge brokers who are supporting access to research and engaging with researchers, community organizations, practitioners, and policy makers. We recommend the use of clear language summaries as part of an institutional strategy for knowledge mobilization.

\section{Acknowledgements}

The authors would like to express their appreciation to the Steering Committee: Stephen Gaetz (Faculty of Education, York University), Simon Cheng (Human Services Planning Coalition, Regional Municipality of York) and Janos Botschner (Policy, Research and Analysis Branch of the Ontario Ministry of Community and Social Services). This work was funded by SSHRC under the "Capturing the Outcomes" competition as well by financial support from the Office of the Vice-President Research \& Innovation, York University. Sincere thanks to students Jason Guriel, Andrei Sedoff, and Paula Elias who drafted, formatted, and posted all the ResearchSnapshot clear language research summaries.

\section{List of abbreviations}

KMb: knowledge mobilization

KT: Knowledge translation

KTE: knowledge transfer and exchange

SCIE: Social Care Institute for Excellence

SSHRC: Social Sciences and Humanities Research Council of Canada

\section{Interviewees}

Interviewee 1, 2009

Interviewee 2, 2009

Interviewee 3, 2009

Interviewee 4, 2009

Interviewee 5, 2009

Interviewee 6, 2009

Interviewee 7, 2009

Interviewee 8, 2009 
Eric Mykhalovskiy, Associate Professor, Dept. Sociology, Faculty of Liberal Arts \& Professional Studies, York University, August 2, 2010

Heather Bullock, Centre for Addition and Mental Health, Toronto, Canada, November 9, 2010

Johanna French, York Region District School Board, Canada, October 20,2010

\section{Websites}

Abstract (Program in Policy Decision-Making). [Website]. URL: http://www.researchtopolicy.ca Arthritis Society. [Website]. URL: http://www.arthritis.ca

At a Glance (Social Care Institute for Excellence). [Website]. URL: http://www.scie.org.uk/ publications/ataglance/index.asp

Evidence Bank (Research In Practice). [Website]. URL: http://www.rip.org.uk/research-evidence/ evidencebank

Evidence Boost (Canadian Health Services Research Foundation). [Website]. URL:

http://www.chsrf.ca/PublicationsAndResources/PastSeries/EvidenceBoost.aspx

Fact Sheets (Canadian Centre for Knowledge Mobilization). [Website]. URL: http://cckm.ca/fact_ sheets.htm

Knowledge Library (Evidence for Policy and Practice Information and Coordinating Centre).

[Website]. URL: http://eppi.ioe.ac.uk/cms/Default.aspx?tabid=60

Mythbusters (Canadian Health Services Research Foundation). [Website]. URL: http://www.chsrf.ca/ PublicationsAndResources/Mythbusters.aspx

Ontario Knowledge Network for Applied Education Research. [Website]. URL: http://www.knaerrecrae.ca/

ResearchImpact. [Website]. URL: http://www.researchimpact.ca

ResearchImpact blog. [Website]. URL: http://researchimpact.wordpress.com/

ResearchImpact online database. [Website]. URL: http://www.researchimpact.ca/researchsearch

ResearchImpact. [Twitter Feed]. URL: @ researchimpact; http://Twitter.com/researchimpact

Research Spotlights (Canadian Centre for Knowledge Mobilization). [Website]. URL: http://cckm.ca/ research_spotlights.htm

Social Care Institute for Excellence. [Website]. URL: http://www.scie.org.uk

\section{References}

Cash, D. (2003). Knowledge Systems for Sustainable Development. Proceedings of the National Academy of Sciences, 100, 8086-8091.

Church, E. (2010, January 1). Web Tools Aim to Open the Gates to the Ivory Tower. Globe and Mail. URL: http://www.theglobeandmail.com/news/technology/web-tools-aim-to-open-the-gates-tothe-ivory-tower/article1416720/ [June 25, 2011].

Community Alliance for Research and Engagement. (n.d.). Beyond Scientific Publication: Strategies for Disseminating Research Findings. URL: http://www.yale.edu/bioethics/contribute_ documents/CARE_Dissemination_Strategies_FINAL_eversion.pdf [June 25, 2011].

Cooper, A., \& Levin, B. (2010). Some Canadian Contributions to Understanding Knowledge Mobilization. Evidence and Policy, 6(3), 351.
Scholarly and Research

Communication

VOLUMe 4 / ISSUE 1 / 2013 


\section{Scholarly and Research} Communication

VOLUME 4 / ISSUE 1 / 2013
Estabrooks, C., Thompson, D.S., Lovely, J.E., \& Hofmeyer, A. (2006). A Guide to Knowledge Translation Theory. Journal of Continuing Education in the Health Professions, 26, 25-36.

Estabrooks, C.A., Derksen, L., Winther, C., Lavis, J.N., Scott, S.D., Wallin, L., \& Profetto-McGrath, J. (2008). The Intellectual Structure and Substance of the Knowledge Utilization Field: A Longitudinal Author Co-citation Analysis, 1945 to 2004. Implementation Science, 3(49). URL: http://www.implementationscience.com/content/3/1/49/ [June 25, 2011].

Gagnon, M. (2011). Moving Knowledge to Action Through Dissemination and Exchange. Journal of Clinical Epidemiology, 64, 25.

Gruzd, A., Wellman, B., \& Takhteyev, Y. (2011). Imagining Twitter as an Imagined Community. American Behavioral Scientisi, 55(10), 1294-1318.

Hemsley-Brown, J., \& Sharp C. (2003). The Use of Research to Improve Professional Practice: A Systematic Review of the Literature. Oxford Review of Education, 29(4), 449-471.

Honeycutt, C., \& Herring, S.C. (2009). Beyond Microblogging: Conversation and Collaboration Via Twitter. Proceedings of the 42nd Hawaii International Conference on System Sciences (pp. 1-10). Big Island, HI: IEEE.

Innvaer, S., Vist, G., Trommald, M., \& Oxman, A. (2002). Health Policy Makers' Perceptions of Their Use of Evidence: A Systematic Review. Journal of Health Services Research Policy, 7(4), 239-244.

Jacobson, N., Butterill, D., \& Goering, P. (2004). Organizational Factors that Influence Universitybased Researchers' Engagement in Knowledge Transfer Activities. Science Communication, 25(3), 246-259.

Java, A., Song, X., Finin, T., \& Tseng, B. (2007). Why We Twitter: Understanding Microblogging Usage and Communities. Proceedings of the 9 th WebKDD and 1st SNA-KDD workshop on: Web mining and social network analysis. San Jose, CA. URL: http://ebiquity.umbc.edu/_file_ directory_/papers/369.pdf [June 25, 2011].

Kaushik, A. (2007, August 6). Standard Metrics Revisited \#3: Bounce rate [Web log post]. URL: http://www.kaushik.net/avinash/2007/o8/standard-metrics-revisited-3-bounce-rate.html [June $25,2011]$.

Lavis, J., Ross, S., McLeod, C., \& Gildner, A. (2003). Measuring the Impact of Health Research: Assessment and Accountability in the Health Sector. Journal of Health Services Research Policy, $8(3), 165-70$.

Lavis, J., Davies, H., Oxman, A., Denis, J-L., Golden-Biddle, K., \& Ferlie, E. (2005). Towards Systematic Reviews that Inform Health Care Management and Policy-making. Journal of Health Services Research Policy, 10 (Suppl. 1), 35-48.

Mazur, B. (2000). Revisiting Plain Language. Technical Communication, 47(2), 205-211.

Meagher, L., Lyall, C., \& Nutley, S. (2008). Flows of Knowledge, Expertise and Influence: A Method for Assessing Policy and Practice Impacts from Social Science Research. Research Evaluation, $17(3), 163-173$.

Michaels, S. (2009). Matching Knowledge Brokering Strategies to Environmental Policy Problems and Settings. Environmental Science \& Policy, 12(7), 994-1011.

Mitton, C., Adair, C.E., McKenzie, E., Patten, P., Wayne-Perry, B., \& Smith, N. (2009). Designing a Knowledge Transfer and Exchange Strategy for the Alberta Depression Initiative: Contributions of Qualitative Research with Key Stakeholders. International Journal of Mental Health Systems, 3(11). doi:10.1186/1752-4458-3-11.

Murmann, J.P. (2003). Knowledge and competitive advantage. Cambridge, UK: Cambridge University Press.

Orwell, G. (1946). Politics and the English Language. URL: https://www.mtholyoke.edu/acad/intrel/orwell46.htm [May 19, 2012].

Phipps, D. \& Shapson, S. (2009). Knowledge Mobilization Builds Local Research Collaborations for 
Social Innovation. Evidence \& Policy, 5(3), 211-227.

Phipps, D. (2011). A Report Detailing the Development of a University-Based

Knowledge Mobilization Unit that Enhances Research Outreach and Engagement. Scholarly

and Research Communication, 2(2), 1-13. URL: http://src-online.ca/index.php/src/article/ viewFile/31/57 [May 19, 2012].

Sangwan, S., Guan, C., \& Siguaw, J.A. (2009). Virtual Social Networks: Toward a Research Agenda. International Journal of Virtual Communities and Social Networking, 1(1), 1-13.

Twitter Blog. (2011). \#numbers. URL: http://blog.Twitter.com/2011/o3/numbers.html [May 19, 2012].

Ward, D., \& Stone, K. (1992). Serving the State: The Wisconsin Idea Revisited. Educational Record, $73(2), 12-16$.

Watermeyer, R. (2010). Social Network Science: Pedagogy, Dialogue, Deliberation. Journal of Science Communication, o9(01), 1-9. URL: http://jcom.sissa.it/archive/o9/o1/Jcomogo1(2010)Ao4/ Jcomo9o1(2010)Ao4.pdf [June 25, 2012].
Scholarly and Research

Communication

VOLUME 4 / ISSUE 1 / 2013 
Scholarly and Research

\section{Communication}

VOLUME 4 / ISSUE 1 / 2013

\section{Appendix A}

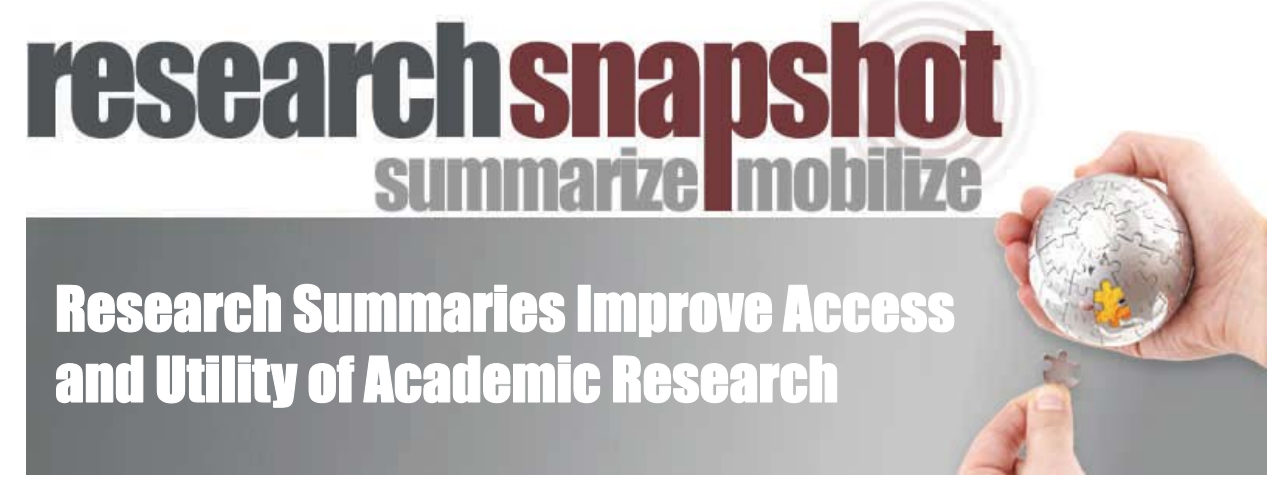

What is this research about?

Academic research is frequently not easily accessible nor is it easily useful for nonacademic decision makers. The Knowledge Mobilization (KM) Unit at York University conducted a pilot project to capture the results and impact of federally funded SSHRC (Social Sciences and Humanities Research Council) research in a simple and effective format. Using Clear Language Writing and Design approaches, the KM Unit wanted to build a library of summaries then test the style, format and usefulness of these summaries in policy or professional settings.

\section{What did the researchers do?}

The KM Unit brought together an advisory group to help support the project and to provide feedback at important times. The most successful elements of existing research summaries were identified to inform development of the final research summary format. Students working for the KM Unit that developed the summaries were trained in Clear Language Writing and Design by an adult educator with this expertise. York Researchers were contacted and asked to share their research
What you need to know:

Current research summaries that are prepared by researchers are not useful or relevant to non academic decision makers. Adopting a standard format that summarizes key outcomes and recommendations and providing greater access to these summaries have been demonstrated to more effectively capture and communicate the outcomes of research for non-academic audiences, connect decision makers to academic researchers and ultimately help academic research to inform decision-making.

findings and project summaries. Over a 12 week period, 42 Research summaries were developed. These summaries were uniquely branded and formatted to provide important information within one or two pages. In addition to text-based summaries, the KM Unit also piloted audio and video versions of a few summaries. The project team conducted focus groups to test the format, style and usefulness of the summaries. All summaries were placed in a searchable database. The recommendations made by the advisory group and the focus group participants were compiled and placed into a final report. In 
May 2009, the KM Unit is set to launch the Research Summary database and link it to the KM website (www.researchimpact.ca).

\section{What did the researchers find?}

The final format that was developed for the research summaries was one - two pages in length. The results from three focus groups were that $77.6 \%$ of the respondents found the format to be good and $86.6 \%$ found the format useful. The development of alternative formats - longer text version (five - six pages), audio and video - saw a majority state these formats were interesting and useful. Almost all (93\%) respondents favoured an external database to house a library of summaries and $81 \%$ said they would like to be notified by email when new summaries were added to the library.

Students that worked on the project identified an improvement in their writing and an ability to identify important policy or professional recommendations in academic research reports.

\section{How can you use this research?}

The products developed from this research have been designed to provide improved access to academic research. These summaries act like a calling card to show expertise on important subjects. While it was assumed the products from this project would help inform decision-making, they may ultimately help support relationship building between the researcher and a decision maker in a policy or professional setting. Furthermore, this research summary format has also been adopted for research from the natural sciences as well as from the social sciences and humanities.

\section{About the Researcher}

David Phipps is Director of Research Services \& Knowledge Exchange and Adjunct Faculty in the Faculty of Graduate Studies at York University. He leads the Knowledge Mobilization Unit at York and leads Researchlmpact, Canada's knowledge mobilization network.

\section{Keywords}

Research Summary, Research Utility, Knowledge Mobilization, Research

Communication
Knowledge Mobilization at York

York's Knowledge Mobilization Unit provides services and funding for faculty, graduate students, and community organizations seeking to maximize the impact of academic research and expertise on public policy, social programming, and professional practice. It is supported by SSHRC and CIHR grants, and by the Office of the Vice-President Research \& Innovation.

kmunit@yorku.ca

www.researchimpact.ca 